\title{
Development and Assessment of a Criterion for the Application of Brønsted-Evans-Polanyi Relations for Dissociation Catalytic Reactions at Surfaces
}

\author{
Zhao-Bin Ding and Matteo Maestri*(i) \\ Laboratory of Catalysis and Catalytic Processes-Dipartimento di Energia, Politecnico di Milano, via La Masa 34, Milano 20156, \\ Italy
}

Supporting Information

\begin{abstract}
We propose and assess a criterion for the application of Brønsted-Evans-Polanyi (BEP) relations for dissociation reactions at surfaces. A theory-to-theory comparison with density functional theory calculations is presented on different reactions, metal catalysts, and surface terminations. In particular, the activation energies of $\mathrm{CH}, \mathrm{CO}$, and trans-COOH dissociation reactions on (100), (110), (111), and (211) surfaces of $\mathrm{Ni}, \mathrm{Cu}, \mathrm{Rh}, \mathrm{Pd}, \mathrm{Ag}$, and $\mathrm{Pt}$ are considered. We show that both the activation energy and the reaction energy can be decomposed into two contributions that reflect the influence of reactant and products in determining either the activation energy or the reaction

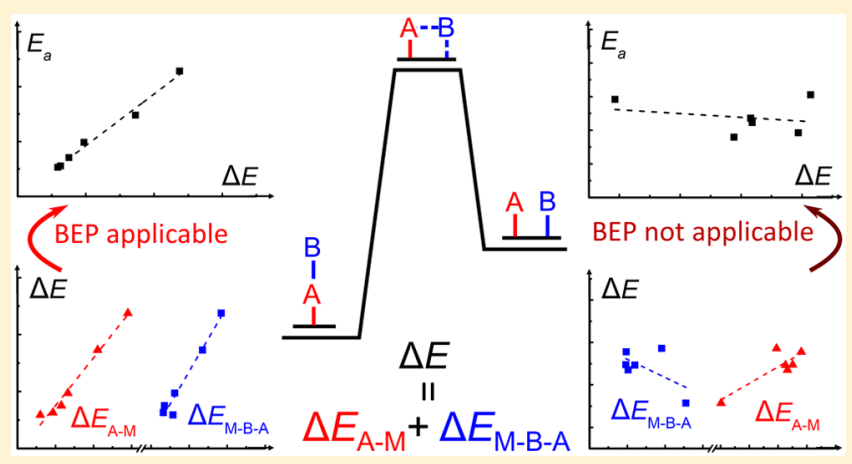
energy. We show that the applicability of the BEP relation implies that the reaction energy and activation energy correlate to these two contributions in the range of conditions to be described by the BEP relation. A lack of correlation between these components for the activation energy is related to a change in the character of the transition state (TS) and this turns out to be incompatible with a BEP relation because it results in a change of the slope of the BEP relation. Our analysis reveals that these two contributions follow the same trends for the activation energy and for the reaction energy when the path is not characterized either by the formation of stable intermediates or by the change of the binding mechanism of the reactant. As such, one can assess whether a BEP relation can be applied or not for a set of conditions only by means of thermochemical calculations and without requiring the identification of the TS along the reaction pathway. We provide evidence that this criterion can be successfully applied for the preliminary discrimination of the applicability of the BEP relations. For instance, on the one hand, our analysis provides evidence that the two contributions are fully anticorrelated for the trans- $\mathrm{COOH}$ dissociation reactions on different metals and surfaces, thus revealing that the reaction is characterized by a change in the TS character. In this situation, no BEP relation can be used to describe the activation energy trend among the different metals and surfaces in full agreement with our DFT calculations. On the other hand, our criterion reveals that the TS character is not expected to change for $\mathrm{CH}$ dissociation reactions both for the same facet, different metals and for same metal, different facets, in good agreement with the DFT calculations of the activation energy. The formation of multiple stable intermediates along the reaction pathways and the change of the binding mechanism of one of the reactants are demonstrated to affect the validity of the criterion. As a whole, our findings make possible an assessment of the applicability of the BEP relation and paves the way toward its use for the exploration of complex reaction networks for different metals and surfaces.
\end{abstract}

\section{INTRODUCTION}

First-principles-based microkinetic modeling of catalytic processes stands at the basis of the mechanistic understanding of the catalysis phenomenon at different operating conditions. ${ }^{1,2}$ The observed reactivity is related to atomistic phenomena, thus paving the way toward the identification of materials for targeted conversions and selectivity. The construction of a predictive microkinetic model, however, requires accounting for all the possible reaction pathways of the process because the prevalent mechanism is expected to vary-at given operating conditions-from metal to metal ${ }^{3-5}$ and from facet to facet. ${ }^{6-9}$ This issue is extremely relevant especially in the quest of developing structure-dependent microkinetic models. Tackling this task by means of firstprinciples calculations is hindered by both the potentially high number of the elementary steps involved in the process and by the complexity in the adsorption configurations of the reactants and the coverage effects. ${ }^{9,10}$ This is also unnecessary because only a small portion of the pathways will contribute to

Received: $\quad$ March 24, 2019

Revised: May 16, 2019

Accepted: May 20, 2019

Published: June 4, 2019 
the prevalent reaction mechanism. ${ }^{11-14}$ To limit the number of reactions that need to be examined by the first-principles calculations, Vlachos and co-workers proposed the hierarchical development of a microkinetic model. ${ }^{15-18}$ Such methodology relies on the estimation of the kinetic parameters using an empirical or a semiempirical method to obtain a sound yet computationally affordable estimation of the rate of each elementary step. ${ }^{19}$ The whole hierarchical framework, however, heavily resorts to the validity of the semiempirical methods, which are usually dismissed as unreliable by the ab initio community. ${ }^{9}$ Therefore, such methods need to be systematically validated and refined by means of first-principles calculations. $^{20}$

One of the most widely used empirical correlations for estimating the reaction barriers is the Brønsted-Evans-Polanyi (BEP) relation ${ }^{21}$ between the reaction barrier $E_{\mathrm{a}}$ and the reaction energy $\Delta E$ :

$$
E_{\mathrm{a}}=\gamma \Delta E+\xi
$$

where both $\gamma$ and $\xi$ are the parameters typically fitted with (experimental or calculated) data of the reactions under different conditions (e.g., different metals and surfaces). ${ }^{22-24}$ Such linear type variation of $E_{\mathrm{a}}$ has been observed for various reactions on the same metal surface structures with high accuracies, and it is found to be also applicable for a class of reactions on the same facet. ${ }^{2,23}$

Previous studies even identified several "universal" BEP relations for the dissociation reactions including a wide range of bonds, i.e., $\mathrm{C}-\mathrm{C}, \mathrm{C}=\mathrm{O}, \mathrm{C}=\mathrm{N}, \mathrm{N}=\mathrm{O}, \mathrm{N}=\mathrm{N}$, and $\mathrm{O}-\mathrm{O}$ bonds, on flat and stepped surfaces, ${ }^{25,26}$ respectively, with a mean absolute error (MAE) lower than $0.35 \mathrm{eV}$. On the contrary, for a reaction on different surface structures, previous studies have found that the intercept in eq $1, \xi$, for different facets can vary by almost $1 \mathrm{eV},{ }^{27}$ which indicates less linearly correlated $E_{\mathrm{a}}$ and $\Delta E$ for the same reaction on different surface structures. This broad difference for the accuracy of the BEP relation reveals that the BEP relation accuracy is sensitive to the local adsorption conditions. ${ }^{28}$ Nevertheless, there are still cases where the difference in $\xi$ is small enough to establish one BEP relation for different facets. ${ }^{29}$

In this situation, a first-principles assessment of the accuracy of a BEP relation is therefore required for clarifying the extent of its applicability for different reactions, metals, and surface structures. This is crucial for the microkinetic modeling of the catalytic processes, especially when the structure of the catalyst may have a profound influence on the catalytic activity. In particular, the development of a general criterion to quickly evaluate the applicability of a BEP relation for a specific reaction on specific reaction sites is demanded.

To address this need, in this work, we propose and assess a criterion for the application of BEP relations for dissociation reactions at surfaces. A theory-to-theory comparison between the estimations of the BEP relation estimations and ab initio density functional theory (DFT) calculations is used to assess the validity and the accuracy of the BEP relations for different reactions. Both BEP relations for the same facet on different metals, and BEP relations for different facets of the same metal are investigated. In particular, the activation energies of $\mathrm{CH}$, $\mathrm{CO}$ and trans-COOH dissociation reactions on (100), (110), (111), and (211) surfaces of $\mathrm{Ni}, \mathrm{Cu}, \mathrm{Rh}, \mathrm{Pd}, \mathrm{Ag}$, and Pt are considered. The key features of the BEP relation accuracy are discussed based on both the analysis of the transition states (TS) structures and energies, and of the thermochemistry of the reaction. We show that both the activation energy $\left(E_{\mathrm{a}}\right)$ and the reaction energy $(\Delta E)$ can be decomposed into two contributions which reflect the influence of reactant and products in determining both the activation energy and the reaction energy. We demonstrate that the applicability of the BEP relation implies that both these contributions are correlated in the range of conditions to be described by the $\mathrm{BEP}$ relation. As such, one can assess whether a BEP relation can be applied or not for a set of conditions only by means of thermochemical calculations and without requiring the identification of the TS along the reaction pathway. As a whole, our findings allow for an assessment of the applicability of the BEP relation in a broad range of conditions and pave the way toward its application for the exploration of complex reaction networks for different metals and surfaces. As such, these results are of direct use for the development of structuredependent microkinetic models in heterogeneous catalysis.

\section{METHODS}

Periodic DFT calculations with Perdew-Burke-Enzerhof (PBE) functionals ${ }^{30}$ are performed with Quantum ESPRESSO code. ${ }^{31}$ All the low-index surfaces, i.e., (100), (110), and (111) surfaces, are modeled by a four-layer $2 \times 2$ slab with the bottom three layers are fixed to simulate the bulk properties. A four-layer $3 \times 3$ slab has been also considered for testing different conditions of coverage. Their first Brillouin zones are sampled with $6 \times 6 \times 1$ Monkhorst-Pack grids ${ }^{32}$ for $2 \times 2$ slabs and with $4 \times 4 \times 1$ Monkhorst-Pack grids for $3 \times 3$ slabs. The stepped (211) surfaces are described by 9-layer $2 \times$ 2 slabs (each slab contains 36 metal atoms) with the bottom 6 layers fixed. Their first Brillouin zones are sampled by $2 \times 6 \times$ 1 Monkhorst-Pack grids. Vacuum (14 $\AA$ ) is added to avoid the interaction between two nearby supercells. The ultrasoft pseudopotentials ${ }^{33}$ are used for the description of the atomic core potentials. The wave functions are described by plane waves with a kinetic energy cutoff of $544 \mathrm{eV}$. Spin-polarized calculations are performed for gas phase radicals as well as for the reactions on ferromagnetic $\mathrm{Ni}$ surfaces. For the trans$\mathrm{COOH}$ reactions, Grimme-D2 $2^{34}$ van der Waals interaction corrections are accounted for describing the weak adsorption of $\mathrm{CO}_{2}$. The residual force on each atom is converged to 0.03 $\mathrm{eV} / \AA$ in the geometric structure optimization.

Transition states (TS) are searched with the climbing imagenudged elastic band (CI-NEB $)^{35}$ method with the force on each atom in each image being converged to $0.05 \mathrm{eV} / \AA$. All the transition states are confirmed by ensuring that their vibrational spectra show only one imaginary mode. The vibrational frequencies are calculated by displacing the atoms on both the adsorbate and the first layer of the metal surface using Atomic Simulations Environment ${ }^{36}$ (ASE).

The reaction energy, $\Delta E$, is defined as the difference between the energy of the global minimum of the coadsorbed products and the energy of the dissociating molecule $(\mathrm{CH}$, $\mathrm{CO}$, or $\mathrm{COOH}$ ) on the most energetically stable site.

The linearity of all the correlations is measured by both the mean absolute error (MAE) and the adjusted $R^{2}$ defined as ${ }^{37}$

$$
R^{2}=1-\frac{(n-1)\left(1-R_{c}^{2}\right)}{n-p-1}
$$

where $n$ is the number of samples, $p$ is the number of independent variables (which equals 1 in all our analyses), and $R_{\mathrm{c}}^{2}$ in eq 2 is the linear correlation coefficient. We use the 
adjusted $R^{2}$ to avoid the bias of the $R_{c}^{2}$ because of the limited size of the samples.

\section{RESULTS AND DISCUSSION}

$\mathrm{CH}$-Dissociation Reaction. We first investigate the $\mathrm{CH}$ dissociation reactions. We take the reaction paths on the $\mathrm{Pd}$ surfaces as an example of the paths on all the surfaces. The details for all the reactions are reported in Section 3 of the Supporting Information. The $\mathrm{CH}$ initially binds on the highcoordination sites, i.e., $4 \mathrm{f}$ site on the (100) and (211) surfaces, long-bridge site on the (110) surfaces, and $3 \mathrm{f}$ sites (hcp or fcc) on the (111) surfaces. In the final state (FS), the C stays on its location in the initial state (IS), while $\mathrm{H}$ moves to the diagonal $4 \mathrm{f}$ site on (100), 3f site on (110), nearby fcc site on (111) and the upper-hcp site that shares one Pd atom with $4 \mathrm{f}$ site on (211). At the TS, the $\mathrm{C}$ atom always remains on the highcoordination site, while the $\mathrm{C}-\mathrm{H}$ bond bends toward the surface and then $\mathrm{H}$ passes through the nearby bridge site. All the TSs are characterized by significant $\mathrm{C}-\mathrm{H}$ bond elongations that are higher than $28 \%$ with respect to the $\mathrm{C}-\mathrm{H}$ bond length in the IS (between 1.10 and $1.13 \AA$ ). Thus, the geometry of the TS for $\mathrm{CH}$ dissociation reactions resembles the configuration of the FS. Intermediates are found for (100) and (211) sites, where the $\mathrm{H}$ moves first to the nearby $4 \mathrm{f}$ site on (100) and to the upper-hcp site above the $4 \mathrm{f}$ site on (211).

Next, we assess the ability of a BEP relation (eq 1) to describe the variation in the activation energies both (i) for the same facet and different metals and (ii) for the same metal and different facets.

Figure 1 reports the correlation between $E_{a}$ and $\Delta E$ on the same facet of different metals.

We find that $E_{\mathrm{a}}$ and $\Delta E$ on every facet are linearly correlated with correlation coefficients (eq 2) higher than 0.95. Also, all the barriers are within a $\pm 10 \%$ error margin with a mean average error (MAE) lower than $0.09 \mathrm{eV}$. Thus, the BEP relation is found to be able to successfully correlate the reaction barriers of $\mathrm{CH}$ dissociation reactions on the same

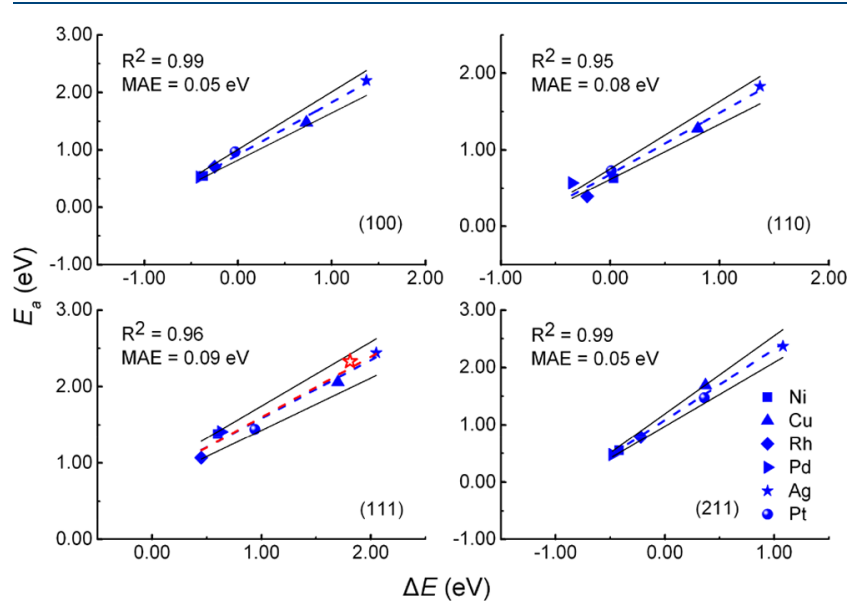

Figure 1. BEP relation of $\mathrm{CH}$ dissociation reactions on different facets. The black solid lines show $\pm 10 \%$ uncertainty of the predicted data. The empty star shows the reaction on $\operatorname{Ag}(111)$ surface at a coverage of $0.11(3 \times 3 \mathrm{slab})$. The $R^{2}$ is the adjusted correlation coefficient (calculated by eq 2 ) of the BEP relations of the reactions modeled by $2 \times 2$ slabs. The red line shows the BEP relation fitted with using both the reactions modeled by $2 \times 2$ slabs and those modeled by $3 \times 3$ slabs. Detailed formulas of BEP relations are listed in Table S5.1. facet of different metals. The slope of all the BEP relations are all greater than 0.70 (in agreement with previous results ${ }^{29}$ ). This reveals a late nature of the TS, also in agreement with the geometry of the TS.

We aim now at a detailed analysis of the reasons why a BEP relation can be established to correlate the variation of the activation energies among the different metals for the same surface for $\mathrm{CH}$ dissociation reactions.

By definition, the activation energy is calculated as

$$
E_{\mathrm{a}}=E_{\mathrm{TS}+\text { slab }}-E_{\mathrm{IS}+\text { slab }}
$$

As proposed by $\mathrm{Hu}$ et al., ${ }^{23}$ the term $E_{\mathrm{TS}+\text { slab }}$ can be decomposed by construction into

$$
E_{\mathrm{TS}+\text { slab }}=E_{\mathrm{C}+\text { slab }}^{\ddagger}+E_{\mathrm{H}+\text { slab }}^{\ddagger}+E_{\text {int }}^{\ddagger}-E_{\text {slab }}
$$

where $E_{\mathrm{C}+\text { slab }}^{\ddagger}$ and $E_{\mathrm{H}+\text { slab }}^{\ddagger}$ are the total energies of adsorbed $\mathrm{C}$, $\mathrm{H}$ with their location frozen in their position at the TS, and $E_{\text {int }}$ is the interaction energy between $\mathrm{C}$ and $\mathrm{H}$ upon coadsorption. By adding and subtracting the $\mathrm{C}-\mathrm{H}$ bond energy $\left(E_{\mathrm{CH}}-E_{\mathrm{C}}-\right.$ $\left.E_{\mathrm{H}}\right)$ in eq 4 and substituting it into eq 3 , we can rearrange eq 3 as follows:

$$
\begin{aligned}
E_{\mathrm{a}}= & {\left[E_{\mathrm{C}+\text { slab }}^{\ddagger}+E_{\mathrm{H}+\text { slab }}^{\ddagger}+E_{\text {int }}^{\ddagger}-E_{\text {slab }}\right]-E_{\mathrm{CH}+\text { slab }} } \\
& +\left(E_{\mathrm{CH}}-E_{\mathrm{C}}-E_{\mathrm{H}}\right)-\left(E_{\mathrm{CH}}-E_{\mathrm{C}}-E_{\mathrm{H}}\right) \\
= & \left(E_{\mathrm{C}+\text { slab }}^{\ddagger}-E_{\text {slab }}-E_{\mathrm{C}}\right)+\left(E_{\mathrm{H}+\text { slab }}^{\ddagger}-E_{\text {slab }}-E_{\mathrm{H}}\right) \\
& -\left(E_{\mathrm{CH}+\text { slab }}-E_{\mathrm{CH}}-E_{\text {slab }}\right) \\
& +\left[E_{\text {int }}^{\ddagger}-\left(E_{\mathrm{CH}}-E_{\mathrm{C}}-E_{\mathrm{H}}\right)\right]
\end{aligned}
$$

By definition, the adsorption energy of a generic adsorbate A is

$$
E_{\mathrm{ads}, \mathrm{A}}=\left(E_{\mathrm{A}+\text { slab }}-E_{\text {slab }}-E_{\mathrm{A}}\right)
$$

Thus, by applying eq 6 to $\mathrm{C}, \mathrm{H}$, and $\mathrm{CH}$, we can rewrite eq 5

$$
\begin{aligned}
& E_{\mathrm{a}}=E_{\mathrm{ads}, \mathrm{C}}^{\ddagger}+E_{\mathrm{ads}, \mathrm{H}}^{\ddagger}-E_{\mathrm{ads}, \mathrm{CH}}+\Delta E_{\mathrm{int}, \mathrm{C}-\mathrm{H}} \\
& =\left(E_{\mathrm{ads}, \mathrm{C}}^{\ddagger}-E_{\mathrm{ads}, \mathrm{CH}}\right)+\left(E_{\mathrm{ads}, \mathrm{H}}^{\ddagger}+\Delta E_{\mathrm{int}, \mathrm{C}-\mathrm{H}}\right) \\
& =\Delta E_{\mathrm{C}-\mathrm{M}, \mathrm{Ts}}+\Delta E_{\mathrm{M}-\mathrm{H}-\mathrm{C}, \mathrm{Ts}}
\end{aligned}
$$

As a whole, the activation energy turns out to be composed of two contributions: $\Delta E_{\mathrm{M}-\mathrm{H}-\mathrm{C}, \mathrm{TS}}$ reflects the variation between the interaction within the $[\mathrm{M}-\mathrm{H}-\mathrm{C}]^{\ddagger}$ complex and the $\mathrm{C}-\mathrm{H}$ bond energy; $\Delta E_{\mathrm{C}-\mathrm{M}, \mathrm{TS}}$ reflects the variation of the metalcarbon $(\mathrm{M}-\mathrm{C})$ interaction in $\mathrm{CH}$ and in TS.

The relative contribution of $\Delta E_{\mathrm{C}-\mathrm{M}, \mathrm{TS}}$ and $\Delta E_{\mathrm{M}-\mathrm{H}-\mathrm{C}, \mathrm{TS}}$ to $E_{\mathrm{a}}$ (eq 7 ) concurs in establishing the character of the TS, i.e., at what extent the TS is influenced by IS or FS. For instance, for the reactions on the same facet of different metals, if $E_{\mathrm{a}}$ linearly correlates to both terms of eq 7, the nature of TS is expected not to be affected by the different metals. Instead, if $E_{\mathrm{a}}$ anticorrelates or does not correlate to both of its components $\left(\Delta E_{\mathrm{C}-\mathrm{M}, \mathrm{TS}}\right.$ and $\Delta E_{\mathrm{M}-\mathrm{H}-\mathrm{C}, \mathrm{TS}}$ in eq 7 ), the nature of the TS is expected to change among the same facet of different metals.

The same decomposition can be also performed for the reaction energy $(\Delta E)$ in full analogy with the $E_{\mathrm{a}}$. In particular, by definition

$$
\Delta E=E_{\mathrm{FS}+\text { slab }}-E_{\mathrm{IS}+\text { slab }}
$$

where $E_{\mathrm{FS}+\text { slab }}$ can be expressed as

$$
E_{\mathrm{FS}+\text { slab }}=E_{\mathrm{C}+\text { slab,FS }}+E_{\mathrm{H}+\text { slab }, \mathrm{FS}}+E_{\text {int }, \mathrm{FS}}-E_{\text {slab }}
$$


Then, by adding and subtracting the bond energy of $\mathrm{CH}$ in the gas phase in eq 8 and by substituting eq 9 into eq 8 , eq 8 thus becomes

$$
\begin{aligned}
& \Delta E=E_{\mathrm{ads}, \mathrm{C}, \mathrm{FS}}+E_{\mathrm{ads}, \mathrm{H}, \mathrm{FS}}-E_{\mathrm{ads}, \mathrm{CH}, \mathrm{FS}}+E_{\mathrm{int}, \mathrm{FS}} \\
& +\left(E_{\mathrm{CH}}-E_{\mathrm{C}}-E_{\mathrm{H}}\right) \\
& =\left[E_{\mathrm{C}+\text { slab }, \mathrm{FS}}+E_{\mathrm{H}+\text { slab }, \mathrm{FS}}+E_{\text {int }, \mathrm{FS}}-E_{\mathrm{slab}}\right]-E_{\mathrm{CH}+\text { slab }} \\
& =\Delta \mathrm{E}_{\mathrm{C}-\mathrm{M}, \mathrm{FS}}+\Delta E_{\mathrm{M}-\mathrm{H}-\mathrm{C}, \mathrm{FS}}
\end{aligned}
$$

In analogy with what found for the activation energy, $\Delta E_{\mathrm{C}-\mathrm{M}, \mathrm{FS}}$ reflects the energy change of the $\mathrm{M}-\mathrm{C}$ bond in IS and $\mathrm{FS}$, whereas $\Delta E_{\mathrm{M}-\mathrm{H}-\mathrm{C}, \mathrm{FS}}$ is related to the variation of $[\mathrm{M}-\mathrm{H}-\mathrm{C}]$ interactions in IS and FS.

According to the BEP relation, $E_{\mathrm{a}}$ and $\Delta E$ are linearly correlated when $\gamma$ and $\xi$ are constant (eq 1). Thus, to satisfy such a requirement, even both components of $\Delta E\left(\Delta E_{\mathrm{C}-\mathrm{M}, \mathrm{FS}}\right.$ and $\Delta E_{\mathrm{M}-\mathrm{H}-\mathrm{C}, \mathrm{FS}}$ in eq 10) must be linearly correlated to their counterparts in TS $\left(\Delta E_{\mathrm{C}-\mathrm{M}, \mathrm{TS}}\right.$ and $\Delta E_{\mathrm{M}-\mathrm{H}-\mathrm{C}, \mathrm{TS}}$ in eq 7$)$. As such, according to our analysis given in eqs 10 and 7 , these requirements are satisfied if

(a) Each contribution of eq $10\left(\Delta E_{\mathrm{C}-\mathrm{M}, \mathrm{FS}}\right.$ and $\Delta E_{\mathrm{M}-\mathrm{H}-\mathrm{C}, \mathrm{FS}}$, respectively) is correlated to the analogous contribution of eq $7\left(\Delta E_{\mathrm{C}-\mathrm{M}, \mathrm{TS}}\right.$ and $\left.\Delta E_{\mathrm{M}-\mathrm{H}-\mathrm{C}, \mathrm{TS}}\right)$, thus implying a correlation between $\Delta E$ and $E_{\mathrm{a}}$.

(b) The two contributions both of eq 10 and of eq 7 are correlated, thus revealing conservation of the character of the TS among the different conditions. In this way, a constant $\gamma($ eq 1$)$ is expected. ${ }^{38}$

To validate this, we verify these requirements for the $\mathrm{CH}$ dissociation on different metals at a given facet, where the BEP relation is found to successfully correlate the DFT data (Figure 1).

We first assess condition a. Figure 2 reports the correlation between the terms of eq 10 and those of eq 7 .

We find that both terms of eq 7 (activation energy) are wellcorrelated to the corresponding ones of eq 10 (reaction energy) with the MAE less than $0.10 \mathrm{eV}$, thus satisfying condition a. This occurs despite the presence on some of the surfaces of stable intermediates along the pathway associated with $\mathrm{H}$ diffusion processes after the formation of the TS. The fact that the migration of $\mathrm{H}$ does not significantly affect the correspondence of the nature of FS to the nature of TS is in line with the negligible effect of coadsorption of $\mathrm{H}$ on the binding energy of $\mathrm{C}^{39}$ In fact, we observe that the binding energy of the coadsorbed $\mathrm{C}$ differs less than $0.07 \mathrm{eV}$ with respect to the value of the $\mathrm{C}$ binding energy at infinite separation, and only 3 of 24 surfaces have that value greater than $0.04 \mathrm{eV}$.

We then examine the correlation between $\Delta E$ and each individual component of eq 10 in order to verify condition $b$, as shown in Figure 3. On (100), (110), and (111) surfaces, we find both terms $\left(\Delta E_{\mathrm{C}-\mathrm{M}, \mathrm{FS}}\right.$ and $\Delta E_{\mathrm{M}-\mathrm{H}-\mathrm{C}, \mathrm{FS}}$ in eq 10$)$ to be linearly correlated to $\Delta E$ for the different metals. For (211) surfaces, the correlation of $\Delta E_{\mathrm{M}-\mathrm{H}-\mathrm{C}, \mathrm{FS}}$ component to $\Delta E$ shows a MAE greater than $0.10 \mathrm{eV}$. However, the range of variation of $\Delta E_{\mathrm{C}-\mathrm{M}, \mathrm{FS}}$, which goes from -1.27 to $0.08 \mathrm{eV}$, is significantly larger than the range of variation of $\Delta E_{\mathrm{M}-\mathrm{H}-\mathrm{C}, \mathrm{FS}}$ (ranging from 0.60 to $0.99 \mathrm{eV}$ ), thus indicating that $\Delta E_{\mathrm{C}-\mathrm{M}, \mathrm{FS}}$ dominates the variation of $\Delta E$. All in all, $\Delta E_{\mathrm{C}-\mathrm{M}, \mathrm{FS}}$ and $\Delta E_{\mathrm{M}-\mathrm{H}-\mathrm{C}, \mathrm{FS}}$ are both linearly correlated to $\Delta E$, thus revealing
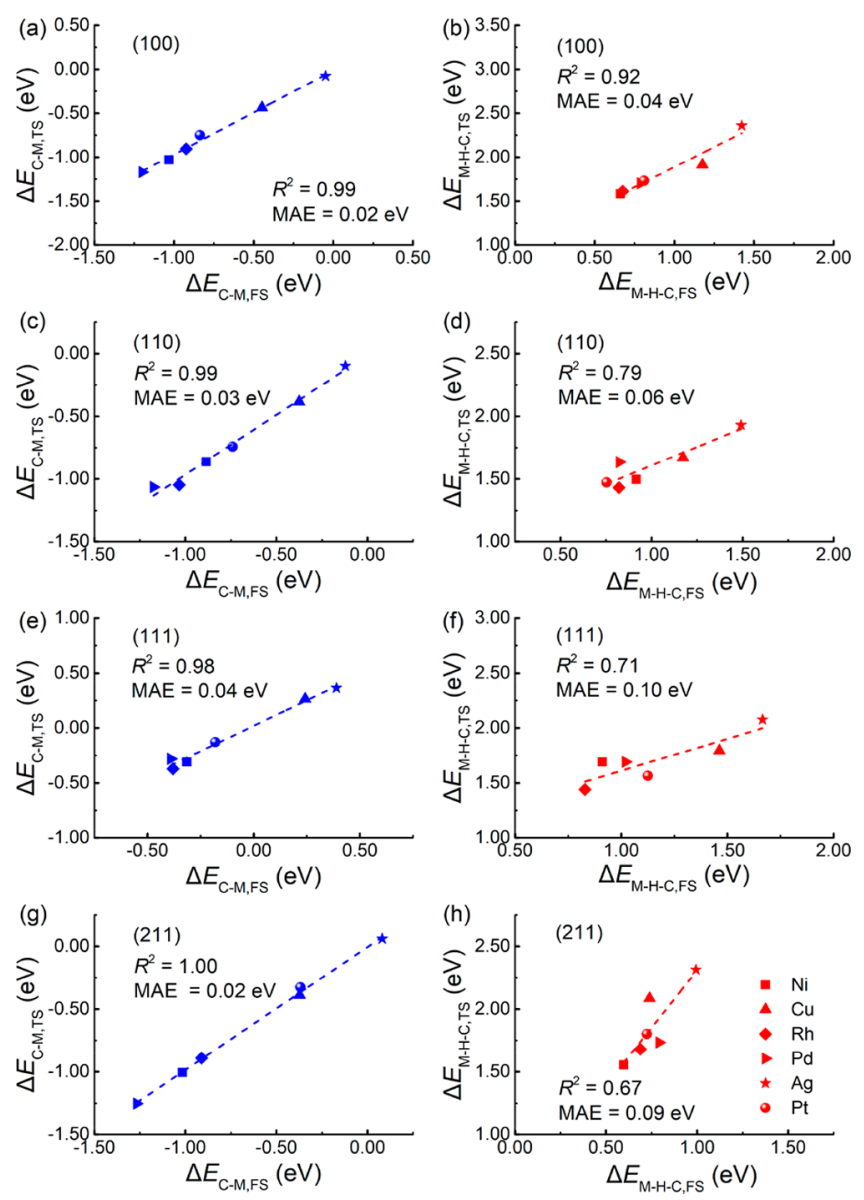

Figure 2. Correlations between $\Delta E_{\mathrm{C}-\mathrm{M}, \mathrm{TS}}$ and $\Delta E_{\mathrm{C}-\mathrm{M}, \mathrm{FS}}$ for $\mathrm{CH}$ dissociation on (a) (100) (c) (110) (e) (111) (g) (211) surfaces and correlations between $\Delta E_{\mathrm{M}-\mathrm{H}-\mathrm{C}, \mathrm{TS}}$ and $\Delta E_{\mathrm{M}-\mathrm{H}-\mathrm{C}, \mathrm{FS}}$ for $\mathrm{CH}$ dissociation on (b) (100) (d) (110) (f) (111) (i) (211) surfaces. Both terms are calculated by eq 7 and eq 10 . The $R^{2}$ is the adjusted correlation coefficient calculated by eq 2 .

that the character of the TS does not change for the reactions occurring on different facets. Such constant TS character satisfies the requirement of a constant $\gamma$ in eq 1 , thus explaining the accuracy of BEP relations for $\mathrm{CH}$ dissociation reactions on the same facets (Figure 1).

As a whole, on the basis of this analysis, we can develop the following criterion to assess whether a BEP relation can be established or not for correlating activation energies and reaction energy in a given range of variation: if the two contributions of eq 10 are linearly correlated with each other for a given range of variation, the nature of TS is not expected to change and as a result a BEP relation can be used. The two terms of eq 10 require only the knowledge of the IS and FS and they do not need any information regarding the TS. Thus, in this situation, one can calculate only two TS to determine the slope and the intercept in eq 1 and predict the other activation energies only on the basis of a BEP relation. For instance, for the conditions reported in Figure 1, we construct a BEP relation only on the basis of the $\mathrm{Ni}(100)$ and $\mathrm{Ag}(100)$ surfaces, and we find its slope and interception to differ from the original ones only by 0.05 and 0.01 , respectively, and with MAE difference of $0.03 \mathrm{eV}$.

We also assessed the $\mathrm{CH}$ dissociation reaction on a $3 \times 3$ supercell of a $\operatorname{Ag}(111)$ surface. Figure 3 shows that the $\Delta E$ and both its components, $\Delta E_{\mathrm{C}-\mathrm{M}, \mathrm{FS}}$ and $\Delta E_{\mathrm{M}-\mathrm{H}-\mathrm{C}, \mathrm{FS}}$, are all well- 

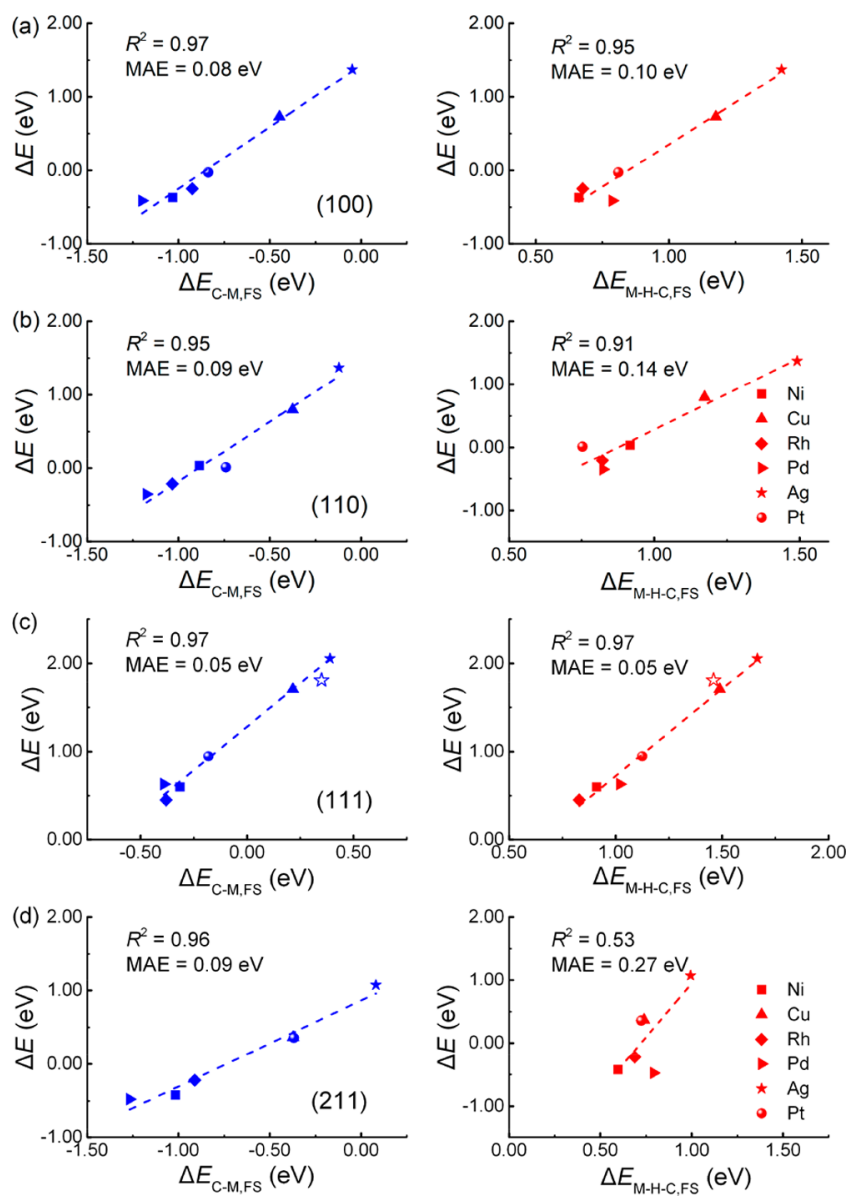

Figure 3. Correlations between $\Delta E$ and both of its components, $E_{\mathrm{C}-\mathrm{M}}$ and $E_{\mathrm{M}-\mathrm{H}-\mathrm{C}}$, for $\mathrm{CH}$ dissociation reactions on (a) (100), (b) (110), (c) (111), and (d) (211) surfaces. The empty star shows the reaction on $\operatorname{Ag}(111)$ surface calculated using a $3 \times 3$ slab. The $R^{2}$ is the adjusted correlation coefficient calculated by eq 2 only with the results from calculations on $2 \times 2$ slabs.

correlated with MAE all equal to $0.07 \mathrm{eV}$ and in full agreement with the BEP relation shown in Figure 1. All in all, this analysis shows that the criterion is applicable for $\mathrm{CH}$ dissociation reactions on the same facet of different metals among the different conditions.

To test the reliability of the proposed criterion, we now apply it to assess whether a BEP relation can be established for $\mathrm{CH}$ dissociation on different surfaces for the same metal.

The correlations between $\Delta E$ and both of its components calculated using eq 10 are shown in Figure 4. In this situation, $\Delta E$ turns out to be less correlated to both components of eq 10, except on Pd surfaces. In particular, on $\mathrm{Cu}$ and $\mathrm{Ag}$ surfaces the MAE for the leading component (i.e., the one which account for the largest variation of $\Delta E)$ of eq $10\left(\Delta E_{\mathrm{C}-\mathrm{M}}\right.$ for $\mathrm{Cu}$ and $\Delta E_{\mathrm{M}-\mathrm{H}-\mathrm{C}}$ for $\mathrm{Ag}$ ) is higher than $0.15 \mathrm{eV}$. This indicates an inconsistent change of both components of eq 10 on the different facets, thus revealing a change of the character of the TS from surface to surface. This is confirmed by the BEP relations for the $\mathrm{CH}$ dissociation reactions on the same metals, that are reported as Figure 5. In fact, in agreement with what predicted by the criterion, $\mathrm{Cu}$ and $\mathrm{Ag}$ show the highest MAE ( 0.20 and $0.19 \mathrm{eV}$, respectively) as a result of the variation of the TS character. $\mathrm{Ni}$ and $\mathrm{Pd}$, instead, where $\Delta E$ correlates to both the components of eq 10 with MAE lower than $0.10 \mathrm{eV}$ and $R^{2}$ higher than 0.90 (Figure 4), the BEP relation turns out
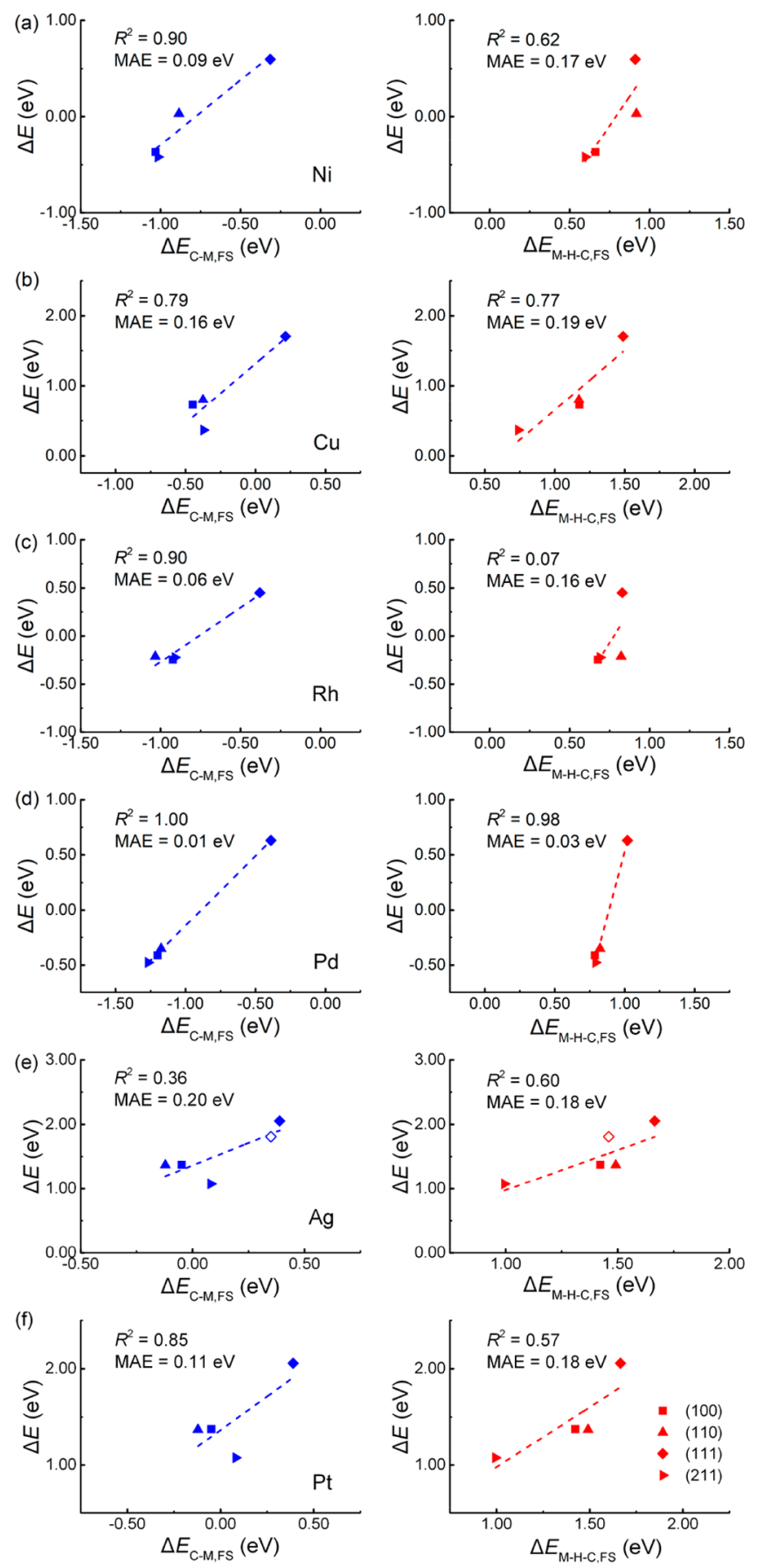

Figure 4. Correlations between $\Delta E$ and both of its components, $\Delta E_{\mathrm{C}-\mathrm{M}, \mathrm{FS}}$ and $\Delta E_{\mathrm{M}-\mathrm{H}-\mathrm{C}, \mathrm{FS}}$, for $\mathrm{CH}$ dissociation reactions on (a) $\mathrm{Ni},(\mathrm{b})$ $\mathrm{Cu}$, (c) Rh, (d) Pd, (e) Ag, and (f) Pt surfaces. The empty rhombus shows the reaction on $\operatorname{Ag}(111)$ surface at a coverage of $0.11(3 \times 3$ slab). The $\mathrm{R}^{2}$ is the adjusted correlation coefficient calculated by eq 2 only with the results from calculations on $2 \times 2$ slabs.

to be more accurate with a MAE lower than $0.10 \mathrm{eV}$. For the case of $\mathrm{Ag}$, we also include in the analysis the case of the $\mathrm{CH}$ dissociation reaction on a $3 \times 3$ slab of a (111) surface. Figure 4 shows that $\Delta E$ and both its components are not correlated to each other with MAE all greater than $0.17 \mathrm{eV}$ and a BEP relation cannot be established in agreement with our criterion (as shown in Figure 5 for $\mathrm{Ag}$ ).

Trans-COOH Dissociation. Next, we investigate the trans$\mathrm{COOH}$ dissociation reactions. Reaction paths on all the facets 

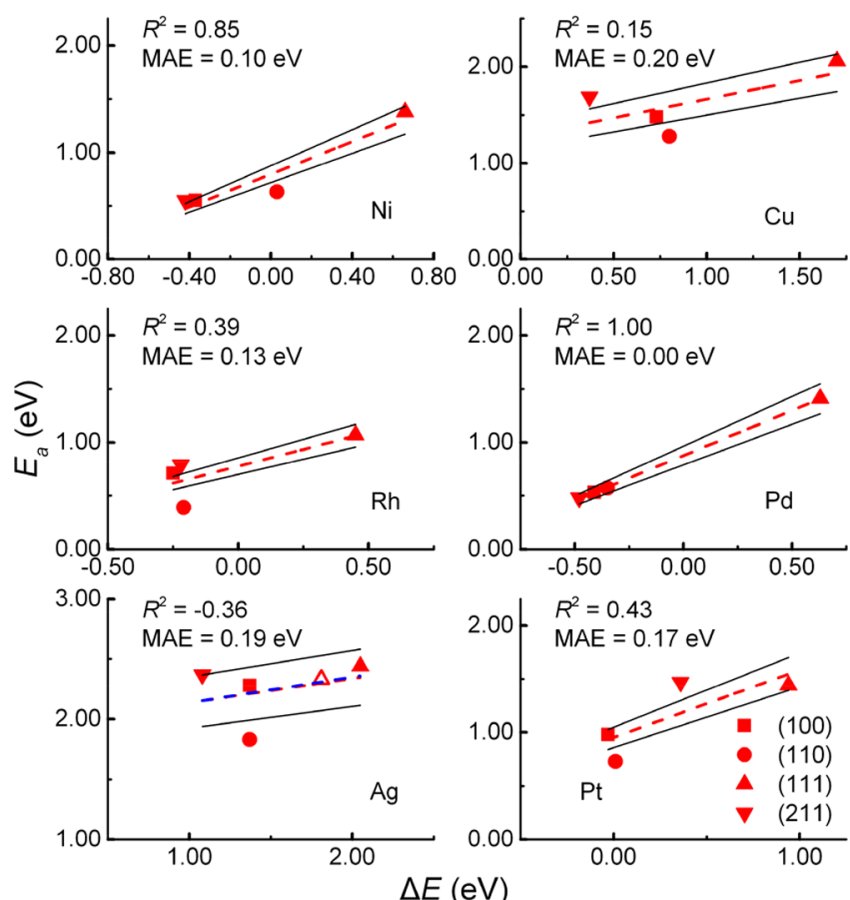

$\Delta E(\mathrm{eV})$

Figure 5. BEP relation of $\mathrm{CH}$ dissociation reactions on different metals The black solid lines show $\pm 10 \%$ uncertainty of the predicted data. The empty triangle shows the reaction on $\operatorname{Ag}(111)$ surface at a coverage of $0.11(3 \times 3 \mathrm{slab})$. The $R^{2}$ is the adjusted correlation coefficient (calculated by eq 2 ) of the BEP relations fitted with using only the reactions at a coverage of $0.25(2 \times 2$ slab $)$. The blue line shows the BEP fitted using both the reactions modeled by $2 \times 2$ slabs and those modeled by $3 \times 3$ slabs. Detailed formulas of BEP relations are listed in Table S5.1.

of Pd surfaces are considered as representative for all the metals. The details for all the reactions are reported in Section 3 of the Supporting Information. We find that on Pd surfaces trans- $\mathrm{COOH}$ prefers binding across two parallel bridges of a $4 \mathrm{f}$ site, short-bridge of (110), bridge of (111) and upper-bridge site of (211) facets with $\mathrm{C}-\mathrm{OH}$ groups binding on top of a metal atom and the other $\mathrm{O}$ atom binds with another metal atom. The lengths of the $\mathrm{O}-\mathrm{H}$ bonds are almost identical to $0.98 \AA$ on all the surfaces. At the TS, we find that, besides the elongation of the $\mathrm{O}-\mathrm{H}$ bond in between 0.46 and $0.52 \AA$, the $\mathrm{M}-\mathrm{C}$ bond elongates on $\mathrm{Pd}(110), \operatorname{Pd}(111)$ and $\operatorname{Pd}(211)$ surfaces up to $0.10 \AA$. It reveals that different from the $\mathrm{CH}$ dissociation reactions, the $\mathrm{Pd}-\mathrm{C}$ bond weakens upon dissociation of $\mathrm{H}$ and the formation of $\mathrm{CO}_{2}$, which is in accord to the weak binding of $\mathrm{CO}_{2}$ that is at least $2.62 \mathrm{eV}$ weaker than the binding energy of trans-COOH. In FS, the $\mathrm{CO}_{2}$ is located on the same site of that in IS on (100) and (211), rotates to the long-bridge site without breaking $\mathrm{M}-\mathrm{C}$ bond on (110) surface and is physisorbed on (111) surface, whereas $\mathrm{H}$ moves to $4 \mathrm{f}$ on (100), $3 \mathrm{f}$ on (110), fcc on (111), and upper-hcp on (211).

We first investigate the correlations between $E_{\mathrm{a}}$ and $\Delta E$ for trans-COOH dissociation reactions on the same facet of different metals. Following the criterion proposed in the previous section, $\Delta E$ is first decomposed into two contributions with respect to the change of the $\mathrm{M}-\mathrm{C}$ bond and the $[\mathrm{M}-\mathrm{H}-\mathrm{O}]$. The two contributions are then examined to derive an indication of the nature of the TS. The correlations between both terms and $\Delta E$ are shown in Figure 6.
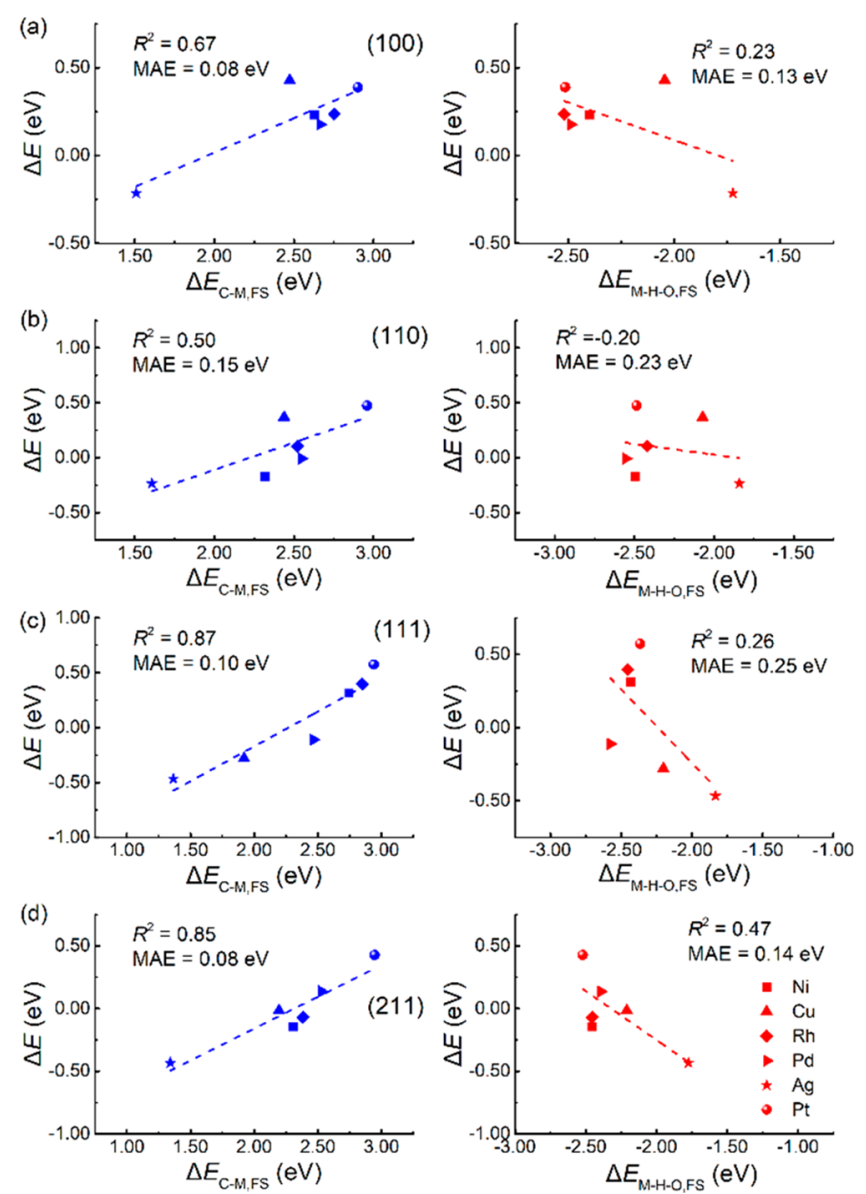

Figure 6. Correlations between $\Delta E$ and both of its components, $\Delta E_{\mathrm{C}-\mathrm{M}, \mathrm{FS}}$ and $\Delta E_{\mathrm{M}-\mathrm{H}-\mathrm{O}, \mathrm{FS}}$, for trans- $\mathrm{COOH}$ dissociation reactions on (a) (100) (b) (110) (c) (111) and (d) (211) surfaces. The $\mathrm{R}^{2}$ is the adjusted correlation coefficient calculated by eq 2 .

We can observe that both terms of eq 10 are anticorrelated. This is an indication that the nature of TS is varying from one metal to the other. Thus, the BEP relation is not expected to be able to relate the activation energies.

This is confirmed by the DFT calculations. In fact, as shown in Figure 7, the activation energies for trans- $\mathrm{COOH}$ dissociation reactions on the same facet of different metals cannot be described by a BEP relation $\left(R^{2}\right.$ lower than 0.10$)$ also in agreement with previous investigations. ${ }^{40,41}$ The substantial change of the TS nature (Figure 6) is also reflected in the geometry of the TS, where the M-C elongation varies from nearly 0 on $\mathrm{Ni}$ surfaces to $0.30 \AA$ on $\mathrm{Ag}(111)$, which agrees with our previous studies, ${ }^{42}$ whereas the corresponding $\mathrm{O}-\mathrm{H}$ bond elongation becomes $0.05 \AA$ shorter on $\mathrm{Ag}$ (111) surface compare to those on $\mathrm{Ni}$ surfaces. It is worth noticing that our criterion has been able to identify such change of the TS character only on the basis of the information on reactants and products of the reaction and without the need of locating the TS along the reaction path.

We then consider the trans- $\mathrm{COOH}$ dissociation reactions on different facets of the same metals. The correlation between $\Delta E$ and the two components of eq 10 is reported as Figure 8. We find that both terms of eq 10 are linearly correlated on $\mathrm{Ni}$, $\mathrm{Cu}$, Rh surfaces (MAE lower than $0.10 \mathrm{eV}$ and $R^{2}$ higher than 0.90). This is an indication that the character of the TS is not varying from surface to surface for these metals. In contrast, on 


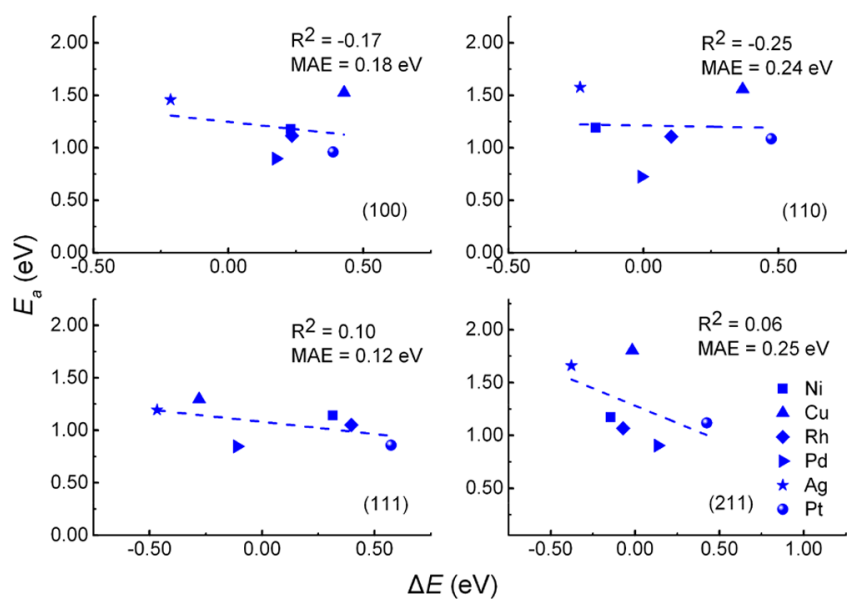

Figure 7. BEP relation of $\mathrm{COOH}$ dissociation reactions on the same facet of different metals. The FS is defined as the coadsorbed $\mathrm{CO}_{2}$ and $\mathrm{H}$ with chemisorbed $\mathrm{CO}_{2}$ being preferred. The $R^{2}$ is the adjusted correlation coefficient calculated by eq 2 . Detailed formulas of BEP relations are listed in Table S5.2.

$\mathrm{Ag}$ and Pd surfaces, both terms of eq 10 are less correlated $\left(R^{2}\right.$ lower than 0.74), which indicates a change of the TS character on these two metals. On the basis of this analysis, our criterion predicts that a BEP relation can correlate $E_{\mathrm{a}}$ and $\Delta E$ on $\mathrm{Ni}, \mathrm{Rh}$, $\mathrm{Pt}$, and $\mathrm{Cu}$ surfaces but not on $\mathrm{Ag}, \mathrm{Pd}$, and $\mathrm{Pt}$. However, this prediction is found to be partially in contrast with the DFT calculations of barriers, as reported in Figure 9.

In fact, on the one hand, as shown in Figure 9, a BEP relation can be established for $\mathrm{Ni}, \mathrm{Rh}, \mathrm{Pt}$, and not for $\mathrm{Ag}$ in agreement with our criterion. On the other hand, the DFT results for $\mathrm{Cu}, \mathrm{Pd}$, and $\mathrm{Pt}$ are in contrast with the prediction of our criterion. Through the analysis of the reaction pathways, this failure of the criterion for $\mathrm{Cu}$ and $\mathrm{Pd}$ is found to be related to the fact that on $\mathrm{Cu}$ and $\mathrm{Pd}$ a change of the $\mathrm{CO}_{2}$ binding mechanism is observed in FS. In particular, on $\mathrm{Cu}$ surfaces, the $\mathrm{CO}_{2}$ is chemisorbed (i.e., $\mathrm{CO}_{2}$ is distorted from the linear structure) on (100) and (110), whereas it is found to be physisorbed (i.e., $\mathrm{CO}_{2}$ maintain linear structure as in gas phase) on (111) and (211) surfaces. Similarly, on Pd, the $\mathrm{CO}_{2}$ is physisorbed on (111) surfaces, while it is chemisorbed on all the other facets. On $\mathrm{Pt}, \mathrm{CO}_{2}$ is chemisorbed at all the facets. However, on (111) facet an intermediate where $\mathrm{CO}_{2}$ is desorbed from the surface is found along the reaction pathway prior the formation of the TS, as shown in Section 3 Table S2.1 of the Supporting Information. All in all, this change of the binding mechanism of $\mathrm{CO}_{2}$ at the different facets does not allow to establish a correlation between the FS and the TS and thus our criterion cannot be applied.

CO Dissociation Reactions. We finally assess the accuracy of BEP relation of $\mathrm{CO}$ dissociation reactions on all the surfaces. We take the reaction paths on the Pd surfaces as examples of the paths on all the metals. The details for all the reactions are reported in Section 3 in the Supporting Information. On (100), (110) surfaces CO prefers to bind on the low-coordination sites, namely bridge site on (100) and (110), whereas on the close-packed (111) surfaces the CO tends to bind on the $3 \mathrm{f}$ sites, and on stepped (211) surfaces both upper-bridge and upper-hcp sites are preferred. In FS, however, the $\mathrm{C}$ always binds on the sites that offer the highest coordination, such as $4 \mathrm{f}$ site on (100) and (211), the long bridge on (110) and fcc site on (111) surface. The significant
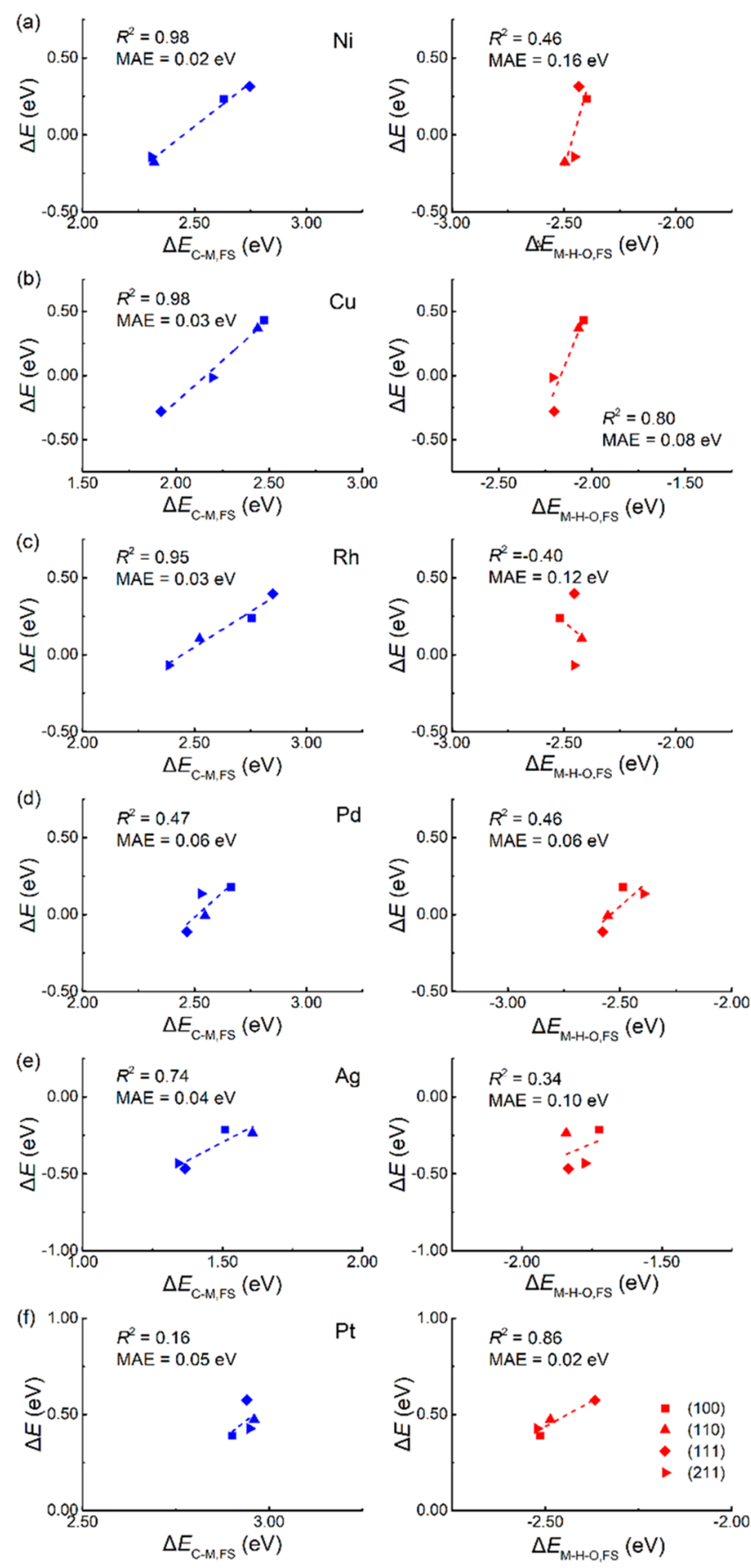

Figure 8. Correlations between $\Delta E$ and both of its components, $\Delta E_{\mathrm{C}-\mathrm{M}, \mathrm{FS}}$ and $\Delta E_{\mathrm{M}-\mathrm{H}-\mathrm{O}, \mathrm{FS}}$, for trans-COOH dissociation reactions on (a) Ni, (b) Cu, (c) Rh, (d) Pd, (e) Ag, and (f) Pt surfaces. The $R^{2}$ is the adjusted correlation coefficient calculated by eq 2 .

difference between the binding site of $\mathrm{CO}$ and $\mathrm{C}$ on (100), (110), and (211) surfaces indicates a migration of all the surface species upon reaction with the formation of additional stable intermediates along the paths (details are reported in Table S2.2). For instance, on the (100) surface, two intermediates are found. One is that the $\mathrm{CO}$ binding on the 4f site, the other is that the coadsorbed $\mathrm{C}$ and $\mathrm{O}$ binding on the neighboring $4 \mathrm{f}$ sites. On (110) surface, two intermediates are also identified. One is that the $\mathrm{CO}$ adsorbs on the longbridge site; the other is that $\mathrm{C}$ is binding on the long-bridge site and $\mathrm{O}$ is binding on the nearby short-bridge site. On (211) 

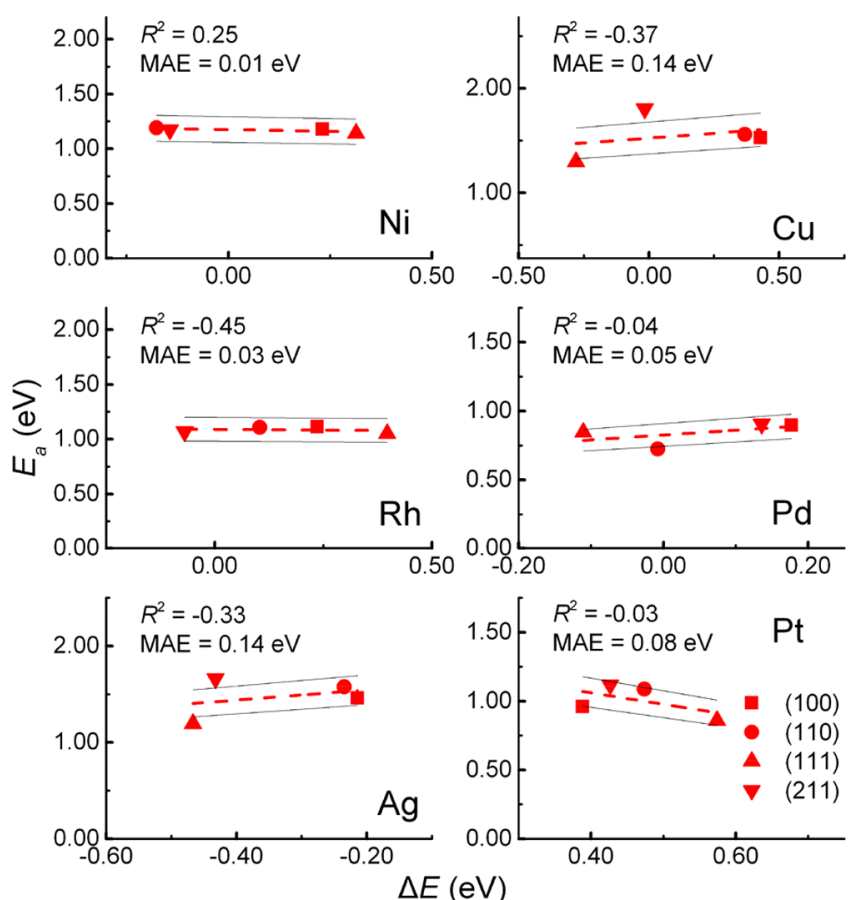

Figure 9. Correlation between $E_{\mathrm{a}}$ and $\Delta E$ of $\mathrm{COOH}$ dissociation reactions on the same facets on different metals. with chemisorbed $\mathrm{CO}_{2}$ being preferred. The black solid lines show $\pm 10 \%$ uncertainty of the predicted data. The $R^{2}$ is the adjusted correlation coefficient calculated by eq 2 . Detailed formulas of BEP relations are listed in Table S5.2.

surface, two local minima, including the $\mathrm{CO}$ that binds on the upper-bridge site and the coadsorbed $\mathrm{C}$ and $\mathrm{O}$ where $\mathrm{C}$ is binding of the $4 \mathrm{f}$ site and the $\mathrm{O}$ is binding on the nearby upper-hcp site, are also identified.

We start by investigating the BEP relations for the reactions on the same facet of different metals. We first apply our criterion to predict the accuracy of the BEP relation. The correlation between $\Delta E$ and both contributions in eq 10, i.e. $\Delta E_{\mathrm{C}-\mathrm{M}, \mathrm{FS}}$ and $\Delta E_{\mathrm{M}-\mathrm{O}-\mathrm{C}, \mathrm{FS}}$ are shown in Figure 10.

We find that on (100), (110), and (211) surfaces $\Delta E$ are less correlated to both contributions $\Delta E_{\mathrm{C}-\mathrm{M}, \mathrm{FS}}$ and $\Delta E_{\mathrm{M}-\mathrm{O}-\mathrm{C}, \mathrm{FS}}$ of eq $10\left(R^{2}\right.$ lower than 0.8 and MAE higher than $\left.0.40 \mathrm{eV}\right)$, thus indicating a variation of the TS character. As such, a BEP relation cannot be established. In contrast, on (111) surfaces, $\Delta E$ correlates more to both contributions ( $\mathrm{R}^{2}$ equals to 0.91 and MAE equals to $0.39 \mathrm{eV}$ ). In agreement with the proposed criterion, this finding indicates a more constant TS character and therefore a BEP relation could be established. However, these predictions do not agree with the DFT results shown in Figure 11.

The same disagreement is found also for the reactions on different surfaces of the same metals, especially for $\mathrm{Ni}, \mathrm{Pd}$, and $\mathrm{Ag}$ (as shown in Figure S5.1 and Figure S6.4). This failure of the criterion is related to the complex reaction paths, which include multiple local minima. In particular, the presence of multiple local minima along the reaction pathway significantly affects the correspondence between the nature of TS and the nature of FS, and thus it reduces the correlation between the two contributions of eq 10 and the two corresponding terms of eq 7 as shown in Figure 12.

In particular, the $\Delta E_{\mathrm{M}-\mathrm{O}-\mathrm{C}, \mathrm{FS}}$ does not correlate to $\Delta E_{\mathrm{M}-\mathrm{O}-\mathrm{C}, \mathrm{TS}}$ with a MAE higher than $0.18 \mathrm{eV}$. This is also in
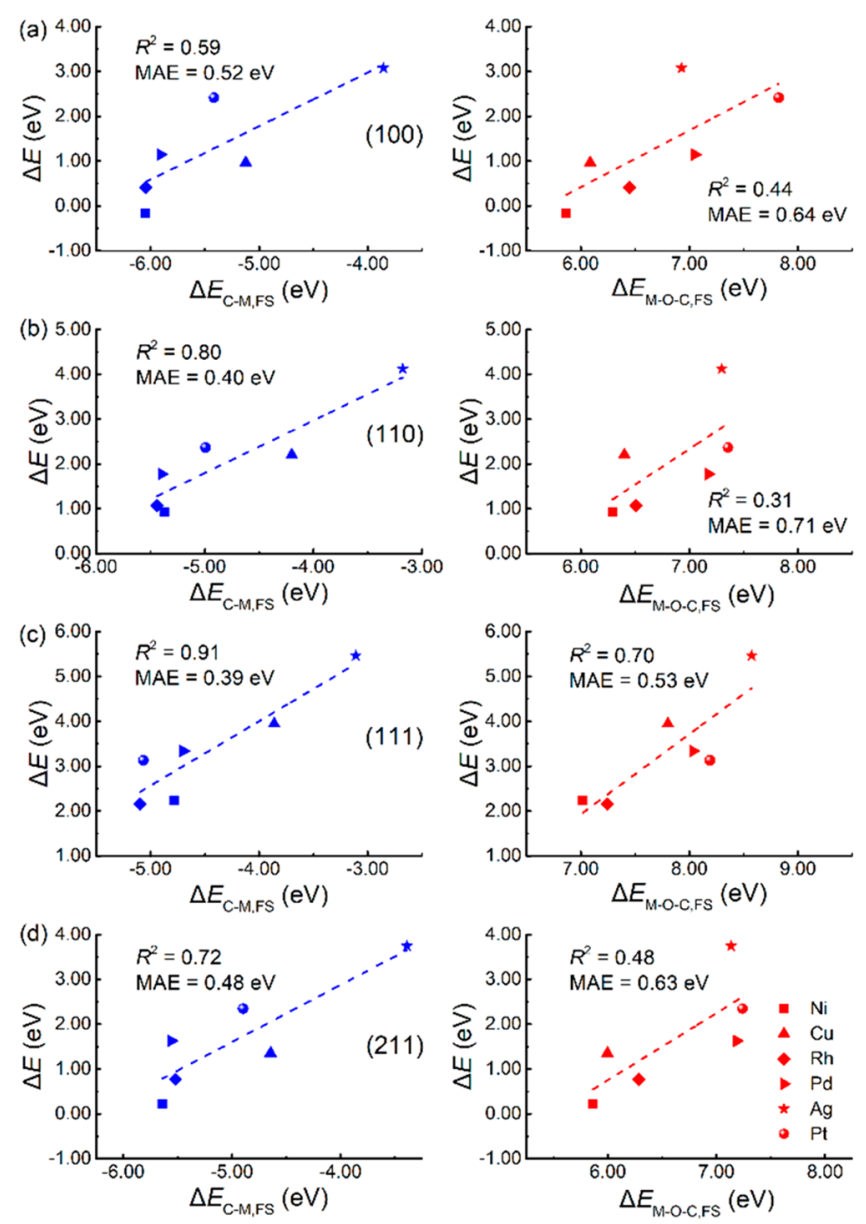

Figure 10. Correlations between $\Delta E$ and both of its components, $\Delta E_{\mathrm{C}-\mathrm{M}, \mathrm{FS}}$ and $\Delta E_{\mathrm{M}-\mathrm{O}-\mathrm{C}, \mathrm{FS}}$, for $\mathrm{CO}$ dissociation reactions on (a) (100), (b) (110), (c) (111), and (d) (211) surfaces. The $R^{2}$ is the adjusted correlation coefficient calculated by eq 2 .

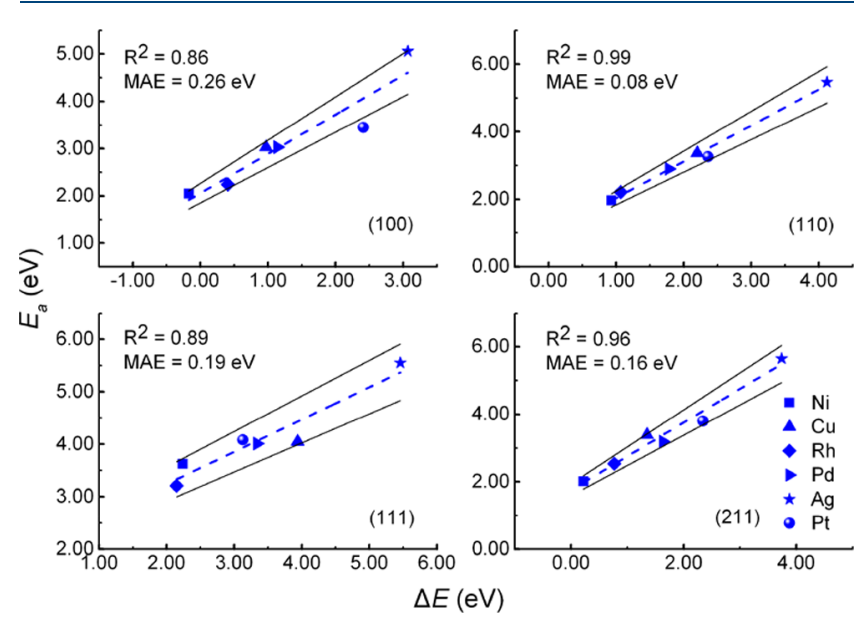

Figure 11. BEP relation of $\mathrm{CO}$ dissociation reactions on different facets. The black solid lines show $\pm 10 \%$ uncertainty of the predicted data. The $R^{2}$ is the adjusted correlation coefficient calculated by eq 2 . Detailed formulas of BEP relations are listed in Table S5.3.

line with the fact that the structural influence of the interaction between $\mathrm{C}$ and $\mathrm{O}$ is significant, as also reported in ref 23. In fact, we find eight surfaces where the binding energies of $\mathrm{O}$ coadsorbed $\mathrm{C}$ differ from that of $\mathrm{C}$ binding energy at infinite separation over $0.15 \mathrm{eV}$. As a whole, the occurrence of multiple 

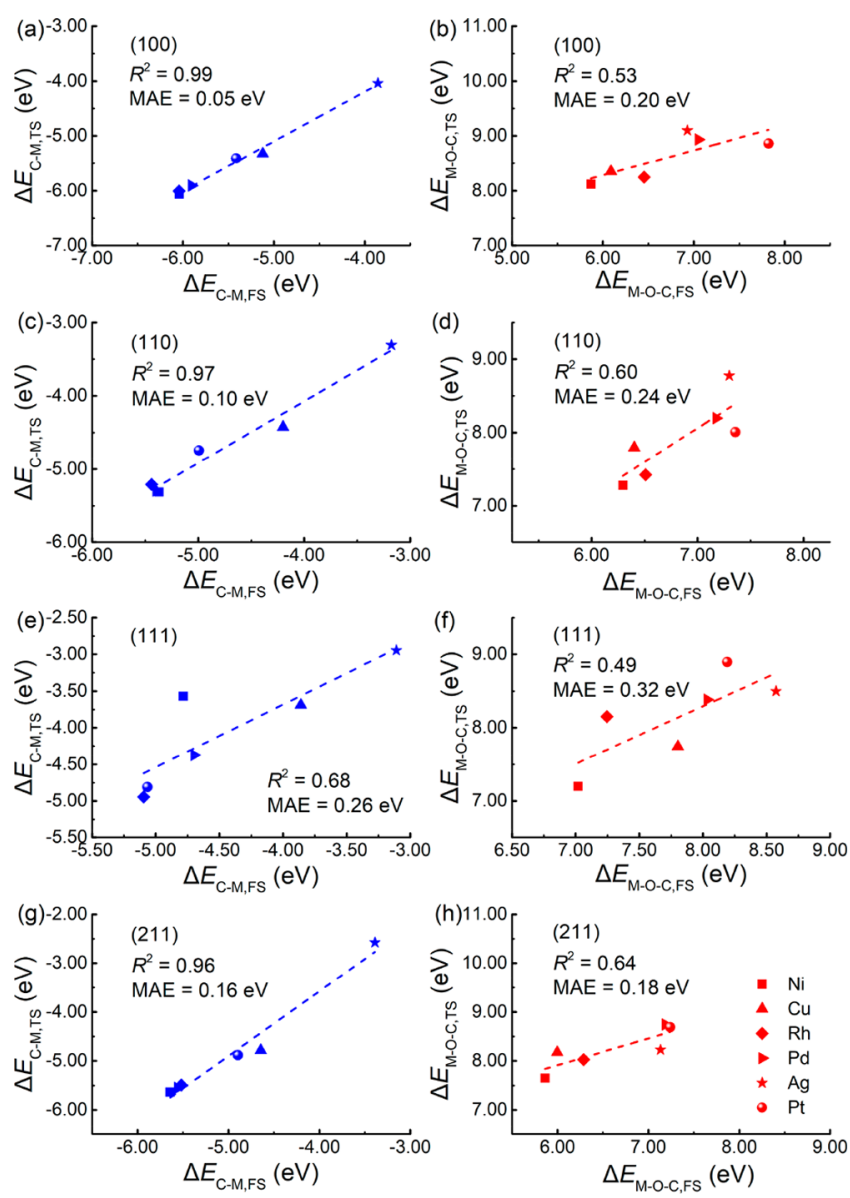

Figure 12. Correlations between $\Delta E_{\mathrm{C}-\mathrm{M}, \mathrm{TS}}$ and $\Delta E_{\mathrm{C}-\mathrm{M}, \mathrm{FS}}$ for $\mathrm{C}-\mathrm{O}$ dissociation on (a) (100), (c) (110), (e) (111), and (g) (211) surfaces and the correlation between $\Delta E_{\mathrm{M}-\mathrm{O}-\mathrm{C}, \mathrm{TS}}$ and $\Delta E_{\mathrm{M}-\mathrm{O}-\mathrm{C}, \mathrm{FS}}$ in FS for $\mathrm{CH}$ dissociation on (b) (100), (d) (110), (f) (111), and (i) (211) surfaces. Both terms are calculated by eq 7 and eq 10 . The $R^{2}$ is the adjusted correlation coefficient calculated by eq 2 .

local minima along the pathway does not allow for relating the FS with TS and thus our criterion cannot be used. This complex pathway can be also inferred by the difference in the location of C in IS and FS and in the sensitivity of the lateral interaction between $\mathrm{C}$ and $\mathrm{O}$ with respect to the coadsorption of $\mathrm{C}$ and $\mathrm{O}$.

\section{CONCLUSIONS}

In this work, we develop a criterion to assess the accuracy of a BEP relation for dissociation reactions only on the basis of thermochemical calculations and without the requirement of explicit TS calculations. The BEP relation is applicable and accurate only when the overall TS character is not varying among the different conditions to be correlated through the $\mathrm{BEP}$ relation. The applicability of the BEP relation (eq 1) is contingent upon satisfying the following conditions: (i) the reaction energy correlates to both of its components that describe different processes involved in the dissociation reactions (eqs 7 and 10), and (ii) the variation of these components is consistent among the different conditions to be represented by the BEP relation (e.g., same metal and different facets in structure-dependent microkinetic modeling). We applied these criterions to predict and assess the applicability of BEP relation for $\mathrm{CH}$, trans- $\mathrm{COOH}$, and $\mathrm{CO}$ dissociation reactions both on the same facets and on the same metals. For
$\mathrm{CH}$ dissociation, we find that the BEP relation is accurate for the reactions on the same facets of different metals, whereas the BEP relation becomes less accurate for the reactions on different facets of the same metal because of a partial change of the character of the TS from facet to facet. For trans-COOH dissociation reactions, the BEP relation is not applicable for the reactions on the same facets of different metals because of the significant difference of the nature of TS from metal to metal. We also found that when the $\mathrm{CO}_{2}$ binding mechanism (physisorption Vs. chemisorption) changes from facet to facet, our criterion fails because the relation between TS and FS is no longer valid. Similarly, for CO dissociation reactions, our criterion becomes less accurate in predicting the relative accuracy of BEP relation. This is because of the complex reaction paths characterized by the formation of several stable intermediate both prior and after the formation of the TS. As a whole, the criterion herein proposed allows for an estimation of the applicability of BEP relation only on the basis of information on the initial and final states. As such, it can substantially reduce the computational effort to develop BEP relations and thus paves the way toward the exploration of complex reaction networks for different metals and surfaces for the development of structure-dependent microkinetic models in heterogeneous catalysis.

\section{ASSOCIATED CONTENT}

\section{Supporting Information}

The Supporting Information is available free of charge on the ACS Publications website at DOI: 10.1021/acs.iecr.9b01628.

(a) Adsorption energies of all the surface species involved in our investigations; (b) final state configurations; (c) reaction paths and geometries of transition states; d) Detailed values of $\Delta E$ and $E_{\mathrm{a}}$ and details of $\mathrm{BEP}$ relations; and (e) detailed values of $\Delta E_{\mathrm{C}-\mathrm{M}, \mathrm{FS}}$, $\Delta E_{\mathrm{M}-\mathrm{A}-\mathrm{C}, \mathrm{FS}}, \Delta E_{\mathrm{C}-\mathrm{M}, \mathrm{TS}}$, and $\Delta E_{\mathrm{M}-\mathrm{A}-\mathrm{C}, \mathrm{TS}}$ (where A denotes $\mathrm{H}$ for $\mathrm{CH}$ dissociation and trans- $\mathrm{COOH}$ dissociation and $\mathrm{O}$ for $\mathrm{CO}$ dissociation reactions) (PDF)

\section{AUTHOR INFORMATION}

\section{Corresponding Author}

*Email: matteo.maestri@polimi.it.

ORCID

Matteo Maestri: 0000-0002-8925-3869

Notes

The authors declare no competing financial interest.

\section{Biographies}

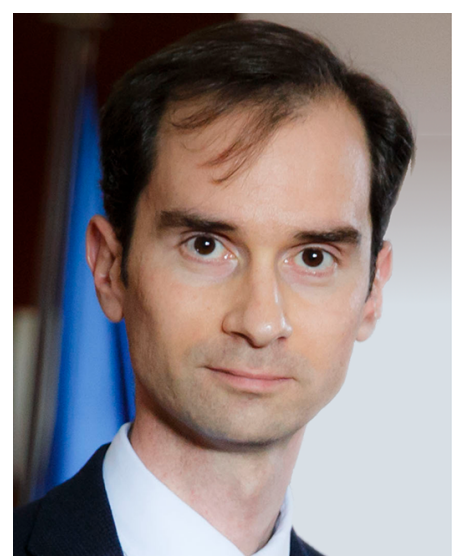


Prof. Matteo Maestri is a full professor of Chemical Engineering at the Politecnico di Milano, Italy. He received his Ph.D. in Chemical Engineering from the Politecnico di Milano in 2008. He has been a visiting scholar at the Center for Catalytic Science and Technology of the Department of Chemical Engineering of the University of Delaware, USA (2006-2007); Alexander von Humboldt Fellow at the Fritz-Haber-Institut der Max-Planck-Gesellschaft in Berlin, Germany (2009-2010); and Alexander von Humboldt Fellow at the Catalysis Research Center (CRC)-Department of Chemistry of the Technische Universität München, Germany (2011). He has received several awards, including the ERC Starting Grant from the European Research Council (2015). His main research interests are fundamental analysis of catalytic kinetics and first-principles-based multiscale modeling of catalytic processes.

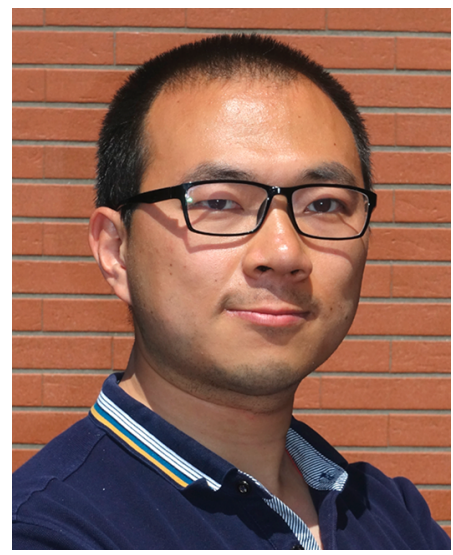

Dr. Zhao-Bin Ding is a postdoctoral researcher at the Department of Energy at the Politecnico di Milano, Italy, in the group of Prof. Matteo Maestri. He received his $\mathrm{PhD}$ in Physical Chemistry from the Peking University, Beijing, in 2015 under the supervision of Prof. Hong Jiang. His main research interests are interface chemistry and first-principles-based multiscale modeling of complex processes at interfaces.

\section{ACKNOWLEDGMENTS}

The projects leading to this work have received funding from the European Research Council (ERC) under the European Union's Horizon 2020 research and innovation programme (Project SHAPE grant agreement 677423). Computational time at CINECA, Bologna, Italy, is gratefully acknowledged. This invited contribution is part of the Industrial \& Engineering Chemistry Research virtual special issue for the 2019 Class of Influential Researchers.

\section{REFERENCES}

(1) Salciccioli, M.; Stamatakis, M.; Caratzoulas, S.; Vlachos, D. G. A Review of Multiscale Modeling of Metal-Catalyzed Reactions: Mechanism Development for Complexity and Emergent Behavior. Chem. Eng. Sci. 2011, 66 (19), 4319-4355.

(2) Goulas, K. A.; Mironenko, A. V.; Jenness, G. R.; Mazal, T.; Vlachos, D. G. Fundamentals of C-O Bond Activation on Metal Oxide Catalysts. Nat. Catal. 2019, 2 (3), 269-276.

(3) Hansgen, D. A.; Vlachos, D. G.; Chen, J. G. Using First Principles to Predict Bimetallic Catalysts for the Ammonia Decomposition Reaction. Nat. Chem. 2010, 2, 484-489.

(4) Schumann, J.; Medford, A. J.; Yoo, J. S.; Zhao, Z.-J.; Bothra, P.; Cao, A.; Studt, F.; Abild-Pedersen, F.; Nørskov, J. K. Selectivity of Synthesis Gas Conversion to $\mathrm{C}_{2+}$ Oxygenates on $\mathrm{Fcc}(111)$ Transition-Metal Surfaces. ACS Catal. 2018, 8 (4), 3447-3453.

(5) Bjelić, A.; Grilc, M.; Huš, M.; Likozar, B. Hydrogenation and Hydrodeoxygenation of Aromatic Lignin Monomers over $\mathrm{Cu} / \mathrm{C}, \mathrm{Ni} /$
C, $\mathrm{Pd} / \mathrm{C}, \mathrm{Pt} / \mathrm{C}, \mathrm{Rh} / \mathrm{C}$ and $\mathrm{Ru} / \mathrm{C}$ Catalysts: Mechanisms, Reaction Micro-Kinetic Modelling and Quantitative Structure-Activity Relationships. Chem. Eng. J. 2019, 359, 305-320.

(6) Ferrin, P.; Mavrikakis, M. Structure Sensitivity of Methanol Electrooxidation on Transition Metals. J. Am. Chem. Soc. 2009, 131 (40), 14381-14389.

(7) Cao, D.; Lu, G.-Q.; Wieckowski, A.; Wasileski, S. A.; Neurock, M. Mechanisms of Methanol Decomposition on Platinum: A Combined Experimental and Ab Initio Approach. J. Phys. Chem. B 2005, 109 (23), 11622-11633.

(8) Zhu, J.; Yang, M.-L.; Yu, Y.; Zhu, Y.-A.; Sui, Z.-J.; Zhou, X.-G.; Holmen, A.; Chen, D. Size-Dependent Reaction Mechanism and Kinetics for Propane Dehydrogenation over Pt Catalysts. ACS Catal. 2015, 5 (11), 6310-6319.

(9) Maestri, M. Escaping the Trap of Complication and Complexity in Multiscale Microkinetic Modelling of Heterogeneous Catalytic Processes. Chem. Commun. 2017, 53, 10244-10254.

(10) Posada-Borbón, A.; Heard, C. J.; Grönbeck, H. Cluster Size Effects in Ethylene Hydrogenation over Palladium. J. Phys. Chem. C 2017, 121 (20), 10870-10875.

(11) Mhadeshwar, A. B.; Vlachos, D. G. Microkinetic Modeling for Water-Promoted CO Oxidation, Water-Gas Shift, and Preferential Oxidation of CO on Pt. J. Phys. Chem. B 2004, 108 (39), 1524615258.

(12) Maestri, M.; Vlachos, D.; Beretta, A.; Groppi, G.; Tronconi, E. Steam and Dry Reforming of Methane on Rh: Microkinetic Analysis and Hierarchy of Kinetic Models. J. Catal. 2008, 259 (2), 211-222.

(13) Filot, I. A. W.; Van Santen, R. A.; Hensen, E. J. M. The Optimally Performing Fischer-Tropsch Catalyst. Angew. Chem., Int. Ed. 2014, 53 (47), 12746-12750.

(14) Susnow, R. G.; Dean, A. M.; Green, W. H.; Peczak, P.; Broadbelt, L. J. Rate-Based Construction of Kinetic Models for Complex Systems. J. Phys. Chem. A 1997, 101, 3731.

(15) Mhadeshwar, A. B.; Vlachos, D. G. Hierarchical, Multiscale Surface Reaction Mechanism Development: CO and H-2 Oxidation, Water-Gas Shift, and Preferential Oxidation of $\mathrm{CO}$ on Rh. J. Catal. 2005, 234 (1), 48-63.

(16) Salciccioli, M.; Chen, Y.; Vlachos, D. G. Microkinetic Modeling and Reduced Rate Expressions of Ethylene Hydrogenation and Ethane Hydrogenolysis on Platinum. Ind. Eng. Chem. Res. 2011, 50 (1), 28-40.

(17) Maestri, M.; Livio, D.; Beretta, A.; Groppi, G. Hierarchical Refinement of Microkinetic Models: Assessment of the Role of the WGS and r-WGS Pathways in CH 4 Partial Oxidation on Rh. Ind. Eng. Chem. Res. 2014, 53 (27), 10914-10928.

(18) Vlachos, D. G.; Mhadeshwar, A. B.; Kaisare, N. S. Hierarchical Multiscale Model-Based Design of Experiments, Catalysts, and Reactors for Fuel Processing. Comput. Chem. Eng. 2006, 30 (1012), $1712-1724$.

(19) Sutton, J. E.; Vlachos, D. G. Building Large Microkinetic Models with First-Principles' Accuracy at Reduced Computational Cost. Chem. Eng. Sci. 2015, 121, 190-199.

(20) Maestri, M.; Reuter, K. Semiempirical Rate Constants for Complex Chemical Kinetics: First-Principles Assessment and Rational Refinement. Angew. Chem., Int. Ed. 2011, 50 (5), 1194-1197.

(21) Evans, M. G.; Polanyi, M. Inertia and Driving Force of Chemical Reactions. Trans. Faraday Soc. 1938, 34, 11-24.

(22) Sutton, J. E.; Vlachos, D. G. A Theoretical and Computational Analysis of Linear Free Energy Relations for the Estimation of Activation Energies. ACS Catal. 2012, 2 (8), 1624-1634.

(23) Michaelides, A.; Liu, Z.-P.; Zhang, C. J.; Alavi, A.; King, D. A.; $\mathrm{Hu}$, P. Identification of General Linear Relationships between Activation Energies and Enthalpy Changes for Dissociation Reactions at Surfaces. J. Am. Chem. Soc. 2003, 125 (13), 3704.

(24) Deshlahra, P.; Iglesia, E. Reactivity and Selectivity Descriptors for the Activation of C-H Bonds in Hydrocarbons and Oxygenates on Metal Oxides. J. Phys. Chem. C 2016, 120 (30), 16741-16760.

(25) Nørskov, J. K.; Bligaard, T.; Logadottir, A.; Bahn, S.; Hansen, L. B.; Bollinger, M.; Bengaard, H.; Hammer, B.; Sljivancanin, Z.; 
Mavrikakis, M.; et al. Universality in Heterogeneous Catalysis. J. Catal. 2002, 209 (2), 275-278.

(26) Wang, S.; Temel, B.; Shen, J.; Jones, G.; Grabow, L. C.; Studt, F.; Bligaard, T.; Abild-Pedersen, F.; Christensen, C. H.; Nørskov, J. K. Universal Brønsted-Evans-Polanyi Relations for C-C, C-O, C-N, N-O, N-N, and O-O Dissociation Reactions. Catal. Lett. 2011, 141 (3), 370-373.

(27) Falsig, H.; Shen, J.; Khan, T. S.; Guo, W.; Jones, G.; Dahl, S.; Bligaard, T. On the Structure Sensitivity of Direct NO Decomposition over Low-Index Transition Metal Facets. Top. Catal. 2014, 57 (1-4), $80-88$.

(28) Montemore, M. M.; Medlin, J. W. Scaling Relations between Adsorption Energies for Computational Screening and Design of Catalysts. Catal. Sci. Technol. 2014, 4 (11), 3748-3761.

(29) Wang, S.; Petzold, V.; Tripkovic, V.; Kleis, J.; Howalt, J. G.; Skúlason, E.; Fernández, E. M.; Hvolbæk, B.; Jones, G.; Toftelund, A.; et al. Universal Transition State Scaling Relations for (de)Hydrogenation over Transition Metals. Phys. Chem. Chem. Phys. 2011, 13 (46), 20760.

(30) Perdew, J. P.; Burke, K.; Ernzerhof, M. Generalized Gradient Approximation Made Simple. Phys. Rev. Lett. 1996, 77 (18), 38653868.

(31) Giannozzi, P.; Baroni, S.; Bonini, N.; Calandra, M.; Car, R.; Cavazzoni, C.; Ceresoli, D.; Chiarotti, G. L.; Cococcioni, M.; Dabo, I. QUANTUM ESPRESSO: A Modular and Open-Source Software Project for Quantum Simulations of Materials. J. Phys.: Condens. Matter 2009, 21 (39), 395502.

(32) Monkhorst, H. J.; Pack, J. D. Special Points for Brillouin-Zone Integrations. Phys. Rev. B 1976, 13 (12), 5188-5192.

(33) Giannozzi, P. http://www.quantum-espresso.org/ pseudopotentials/.

(34) Grimme, S. Semiempirical GGA-Type Density Functional Constructed with a Long-Range Dispersion Correction. J. Comput. Chem. 2006, 27 (15), 1787-1799.

(35) Henkelman, G.; Uberuaga, B. P.; Jónsson, H. A Climbing Image Nudged Elastic Band Method for Finding Saddle Points and Minimum Energy Paths. J. Chem. Phys. 2000, 113 (22), 9901-9904.

(36) Hjorth Larsen, A.; Jørgen Mortensen, J.; Blomqvist, J.; Castelli,

I. E.; Christensen, R.; Dułak, M.; Friis, J.; Groves, M. N.; Hammer, B.;

Hargus, C.; et al. The Atomic Simulation Environment-a Python

Library for Working with Atoms. J. Phys.: Condens. Matter 2017, 29 (27), 273002.

(37) Cohen, J.; Cohen, P.; West, S. G.; Aiken, L. S. Applied Multiple Regression/Correlation Analysis for the Behavioral Sciences, 3rd ed.; Lawrence Erlbaum Associates Publishers: Mahwah, NJ, 2003.

(38) Grabow, L. C.; Gokhale, A. A.; Evans, S. T.; Dumesic, J. A.; Mavrikakis, M. Mechanism of the Water Gas Shift Reaction on Pt: First Principles, Experiments, and Microkinetic Modeling. J. Phys. Chem. C 2008, 112 (12), 4608-4617.

(39) Ciobica, I. M.; Kleyn, A. W.; van Santen, R. A. Adsorption and Coadsorption of $\mathrm{CO}$ and $\mathrm{H}$ on Ruthenium Surfaces. J. Phys. Chem. B 2003, 107 (1), 164-172.

(40) Yoo, J. S.; Abild-Pedersen, F.; Nørskov, J. K.; Studt, F. Theoretical Analysis of Transition-Metal Catalysts for Formic Acid Decomposition. ACS Catal. 2014, 4 (4), 1226-1233.

(41) Herron, J. A.; Scaranto, J.; Ferrin, P.; Li, S.; Mavrikakis, M. Trends in Formic Acid Decomposition on Model Transition Metal Surfaces: A Density Functional Theory Study. ACS Catal. 2014, 4 (12), 4434-4445.

(42) Dietz, L.; Piccinin, S.; Maestri, M. Mechanistic Insights into CO 2 Activation via Reverse Water-Gas Shift on Metal Surfaces. J. Phys. Chem. C 2015, 119 (9), 4959-4966. 